Graaff, F.M. de, Francke, A.L.

Home care for terminally ill Turks and Moroccans and their families in the Netherlands: carers' experiences and factors influencing ease of access and use of services.

International Journal of Nursing Studies: 40, 2003, nr. 8, p. 797-805

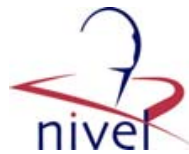

\begin{tabular}{l|l} 
Postprint Version & 1.0 \\
\hline Journal website & $\underline{\text { http://www.sciencedirect.com/science/journal/00207489 }}$ \\
\hline Pubmed link & $\begin{array}{l}\text { http://www.ncbi.nlm.nih.gov/entrez/query.fcgi?cmd=Retrieve\&db=pubmed\&dop } \\
\text { t=Abstract\&list_uids=14568362\&query_hl=27\&itool=pubmed_docsum }\end{array}$ \\
\hline DOI & $10.1016 /$ S0020-7489(03)00078-6
\end{tabular}

\title{
Home care for terminally ill Turks and Moroccans and their families in the Netherlands: carers' experiences and factors influencing ease of access and use of services
}

\author{
F.M. DE GRAAFF*, A.L. FRANCKE \\ Netherlands Institute of Health Services Research (Nivel) Foundation, P.O. Box 1568, Utrecht, BN, \\ Netherlands
}

\begin{abstract}
The aim of this study was to explore the experiences of relatives of elderly terminally ill Turks and Moroccans regarding Dutch professional home care and the barriers to the use this care. Nine Turkish and ten Moroccan family members, who recently looked after dying members of their families, were interviewed using a semi-structured topic list. The data was analyzed using the method described by Glaser and Strauss. The results of this study make it clear that there is no uniform pattern in the use of home care. However, family members who did use home care facilities were all satisfied. Furthermore, on the basis of this study, several factors influencing access to and use of home care were discerned, e.g., illness, family structure, decision making, pressure from the community, information and formal referrals. In addition, the authors found that 'preferences regarding family care' influenced all former factors.
\end{abstract}

\section{INTRODUCTION}

Although the Netherlands has been a haven for immigrants for decades, little is known about the experience of care and preferences of elderly immigrants in the Netherlands. At the moment Moroccans and Turks are interesting groups of immigrants, because the number of elderly Moroccans and Turks over the age of 55 is increasing very fast. In 1996 15,380 Turks and 13,875 Moroccans over 55 years of age were living in the Netherlands, in 2001 their numbers were 23,315 and 20,470 (Central Bureau of Statistics, 2002), an increase over 5 years of $49 \%$. The study presented was carried out in order to provide more insight into clients' experiences regarding the home care of terminally ill Turks and Moroccans and their families.

Professional home care organizations suppose that terminally ill Turks and Moroccans and their families do not use the care available very often. However, these organizations are not sure of this because the ethnicity of their clients is not recorded by all home care organizations, and care research with a focus on terminally ill Turks and Moroccans in the Netherlands is not available. Some studies have looked at the experience of care and preferences of elderly Turks or Moroccans in the Netherlands in general, though these do not focus on terminal patients. Two of these studies were carried out among intermediaries, e.g., social workers, and indicate that the use by Turks and Moroccans of home care services is limited because they are unacquainted with the Dutch home care system (Beljaarts, 1997; Maravelias, 2000). Studies performed by Van Toorn (1994) among elderly 
Graaff, F.M. de, Francke, A.L.

Home care for terminally ill Turks and Moroccans and their families in the Netherlands:

carers' experiences and factors influencing ease of access and use of services.

International Journal of Nursing Studies: 40, 2003, nr. 8, p. 797-805

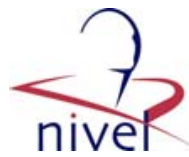

immigrants in Rotterdam, and by Yerden (2000) among elderly Turkish people in the province of North Holland suggest that feelings of honour and shame in the immigrant communities, financial constraints, and the fact that care available is not adapted to the needs of immigrant families also inhibit the use of professional home care. The studies mentioned emphasize the importance of increased data on the experience of Turkish and Moroccan terminally ill patients and their families of home care services. This is particularly important because Turkish and Moroccan terminally ill elderly sometimes suffer from care problems, e.g., decubitus ulcers (Van den Brink, 2000) which can be solved if treated properly, and there is some indication that the relatives can easily become overburdened with the care needs of these clients (Yerden, 2000).

Although Moroccans and Turks are quite different in language and cultural background, both groups are included in this study because their situation in the Netherlands is to a large extent comparable in that immigration from Turkey and Morocco started in 1965 as a response to labour shortages in the Netherlands. Most immigrants from Turkey and Morocco were young at that time and have now reached pensionable age. Although many immigrants dream of returning to their home country, most of them stay in the Netherlands. They are the first cohort of Turkish and Moroccan elderly who, on becoming terminally ill, are potential users of the palliative services of Dutch home care organizations. In this study the following research questions were addressed:

1. What experiences do the Turkish and Moroccan families of terminally ill patients have of Dutch home care in the terminal phase?

2. What factors influence the access to, and use of home care in the terminal phase?

In this article 'home care' means the home care, home nursing, health education and supply of technical aids offered by a professional home care organization in the Netherlands to terminally ill patients and their families at home. Home care is mostly financed by the Dutch government via the General Act on Exceptional Medical Expenses (AWBZ), which is financed by tax revenue. In addition patients pay a small amount per hour or per service. Home care providers are defined according to educational level and specialization as district nurses, enrolled nurses and home helps (Adam and Hutten, 2001), though this article will use the term 'nurses' for all home care providers. These nurses often work closely with the general practitioner, who is responsible for the medical care of terminally ill patients, while they are living at home. Often the general practitioner is the person who initially refers patients to home care, though, independent regional assessment agencies have responsibility for carrying out a formal needs assessment. The system of primary health care based on home care and general practice is well developed in the Netherlands, resulting in a higher percentage of the elderly dying at home than elsewhere (Francke and Willems, 2000).

\section{METHOD}

\subsection{Sample and recruitment}

Although the care experiences of terminal patients themselves are very important, for ethical and practical reasons it was decided to interview relatives. Only relatives of terminally ill Turkish or Moroccan patients, or relatives of Turkish or Moroccan patients who had died after a chronic terminal illness, were included in this study. Relatives of patients who died before the terminal phase were not included. To find enough respondents, the researcher sent written information about the study to more than 100 relevant care organizations (some professional home care organizations, voluntary terminal care organizations, hospices, healthcare centres and general practices in the areas with large numbers of immigrants) and asked to be introduced to potential respondents. In addition, more than 90 Turkish and Moroccan teachers, social workers, active members of mosque organizations and health advisers who were personally known to the researcher, were asked to recruit respondents. The latter procedure had more success than the approach via the formal organizations. As a result 19 respondents were accrued, with a fair distribution of Turkish and Moroccan families and including users and non-users of home care. The researcher also tried to recruit families living in mainly Turkish or Moroccan neighbourhoods in the Netherlands as well as families living in 'white areas' as the former may have different experiences than the latter. Table 1 shows some social and demographic data of the respondents. 
Graaff, F.M. de, Francke, A.L.

Home care for terminally ill Turks and Moroccans and their families in the Netherlands:

carers' experiences and factors influencing ease of access and use of services.

International Journal of Nursing Studies: 40, 2003, nr. 8, p. 797-805

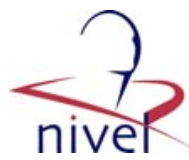

\section{[ TABLE 1 ]}

Informed consent was obtained from each respondent verbally after the first meeting with the interviewing researcher. The respondents' verbal consent and the rest of the interview was recorded on tape. Only one respondent did not give permission for the interview to be recorded on tape. In this case the researcher made notes.

If relatives preferred to talk in their own language rather than in Dutch, an interpreter was organized. Although the researcher speaks Morroccan Arabic and a little Turkish, she has not mastered the Berber languages, and prefers not to misinterpret the data. Six interviews were held with the help of an interpreter: one Turkish and five Moroccan. Nine families in the research sample had used professional home care in the terminal phase of their family members' illness. Only six families had experience of hospital care or nursing home care instead of home care. Two interviews were with the families of terminally ill patients who were still alive. The other interviews were held several months after the death of the patient.

\subsection{Data collection and analysis}

The qualitative method used in this study was based on the principles of the 'grounded theory' developed by Strauss and others (Glaser and Strauss, 1967; Strauss and Corbin, 1990). The grounded theory approach means that the researcher has no clear-cut hypotheses beforehand, but is open to new insights and starts data collection with broad research questions. Based on this information the researcher can devise more accurate research questions. Data collection and analysis are alternating elements of this cyclic research process.

The respondents received some written information about the aim of the study and the topics that would be discussed in the interview. The interviews lasted between 1 and $2 \mathrm{~h}$. Respondents first described the health situation of their terminally ill family member and how the family care was organized. In this context they told the researcher about their experiences (or the lack of experiences) with Dutch home care. Their stories revealed which factors influenced the access to and use of home care. Finally they were invited to evaluate the care process, to describe their care needs and those of their terminally ill family member and to say what types of care (would have) met these needs.

In accordance with the principle of "theoretical saturation" (Glaser and Strauss, 1967) it was decided to stop data collection after 19 interviews, because the last interviews did not give any new information.

The verbatim texts were typed and qualitatively analyzed. The texts were read through many times and codes assigned to important text fragments using Winmax, a computer program for arranging qualitative data. Examples of these codes are: 'personal characteristics', 'family characteristics', 'actions of family carers', 'rituals in terminal phase', 'consciousness being terminally ill', etc. Interviews were read and coded by the coauthor and other researchers to prevent one-sided interpretations of the research data. To improve the quality of the data analysis, interim analyses were discussed with Dutch, Moroccan and Turkish experts. Furthermore, analyses were discussed with members of the steering committee, colleagues and a working group of qualitative researchers, a process known as peer debriefing (Lincoln and Guba, 1985).

\section{RESULTS}

\subsection{Experiences of Dutch professional home care for the terminally ill}

\subsubsection{Use of home care}

The sample included nine users and ten non-users of home care in order to observe the experiences of both groups and to get insight into the differences between the characteristics or living conditions of both groups. The user characteristics of the families appeared to be quite different, ranging from deliberate non-users to the reluctant and elective users. It appeared that non-users intentionally preferred to rely on family care only. They tried to care for the terminally ill within the family, but were often forced to bring the patient to the hospital or nursing home in his last days because they were unable to provide appropriate care at home. The reluctant group included respondents who would have used the facilities of home care if they had been better informed about them. These respondents 
Graaff, F.M. de, Francke, A.L.

Home care for terminally ill Turks and Moroccans and their families in the Netherlands:

carers' experiences and factors influencing ease of access and use of services.

International Journal of Nursing Studies: 40, 2003, nr. 8, p. 797-805

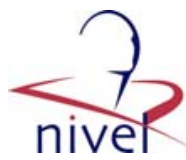

said that they regretted that they had not used home care, because they felt it would have been better for their patient and for themselves. The elective users had enough information about the home care facilities and accepted professional home care for the care needs of the patient and relatives. This group gave us a lot of information about the experience of home care. They felt that professional home care supplements family care and enhanced the quality of care.

None of the users regretted using home care. Some users gave lively descriptions of the loaned nursing aids, such as the movable bed, the trapeze, the decubitus mattress, wheelchair, or alarm. Users were also satisfied with the support they received from the home care personnel. Most nurses who worked in these families were Dutch. Only one Turkish respondent got help from a professional with a Turkish background. In general, professional support meant short home visits by a nurse. Only one Moroccan patient used a special offer of night care for terminal patients.

Several respondents said they were pleased that the nurses instructed them how to manage decubitus ulcers, wounds, injections, etc. They were grateful for the nurses' assistance in supporting the patient in daily activities of living and said that they gave them more information about the illness and its treatment, as the wife of a Moroccan lung cancer patient demonstrated:

I was looking on while she was dealing with treating the wound. Twice or three times a night I cleaned it myself. The nurse showed up to check on the wound, three times a day she came by to clean it and then I said: "I'll take care of the rest"'

The home care users viewed most of the nurses as 'helping friends'. Some users were disappointed that these 'friends' did not visit following the death of their terminally ill family member. Some respondents also argued that home care organizations should employ more Turkish professionals: "This enables my very ill mother to communicate directly with the professional without my interference. She likes to express her feelings and chat to the nurse”'. The terminally ill Turkish and Moroccan patients could not converse easily in Dutch. However, severe communication problems were mentioned more often in connection with doctors than with nurses. Many respondents reported that they had difficulty with the contradictory questions of their family member and the doctors. In one case a general practitioner asked the daughter in law of a terminal patient to tell the patient that she would die soon. Being only the daughter in law, it was difficult and culturally inappropriate for her to relay this message when other family members were gathered in the same room.

\subsubsection{Access to home care}

Respondents remembered that the home care started with a formal needs assessment interview, and a lot of questions about the needs of the patient and the family. However, in their view it was their general practitioner who usually suggested the use of home care and they were grateful to the general practitioner for this. Other families received home care after being discharged from hospital. They observed that their medical specialist in the hospital referred them for home care. Families who were not informed about the availability of home care blamed their general practitioner for the lack of this information.

He just thinks it's sad. He really regrets the fact that his mother didn't die at home, surrounded by her family. He says: “The doctor might have known, that this woman didn't have long to live anymore, and why couldn't he inform the family"' [about the fact this woman might have died at home with the aid of home care services]. (Interpreter rendering the words of a Moroccan respondent whose mother died at the hospital without any of her family)

\subsection{Factors influencing the access and use of professional and voluntary home care}

In analyzing the data, some factors influencing access to and use of home care were discerned such as 'illness and cause of death', 'family structure', 'decision making in the family', 'pressure from the community', 'information and support from informal and professional care providers' and 'formal referrals'. In addition another factor, namely 'family preferences regarding family care', was highlighted as affecting these other variables. 
Graaff, F.M. de, Francke, A.L.

Home care for terminally ill Turks and Moroccans and their families in the Netherlands:

carers' experiences and factors influencing ease of access and use of services.

International Journal of Nursing Studies: 40, 2003, nr. 8, p. 797-805

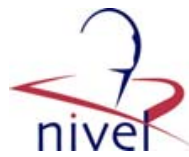

\section{[ FIGURE 1 ]}

Fig. 1 illustrates the relationship between the factors that influence access to and use of home care. It appeared that all factors playa role in the Turkish and the Moroccan terminal care-situation, but the influence of some factors is stronger in one of these groups. In the subsequent paragraphs the different factors and their effects on the care situation in Turkish and Moroccan families will be further explained, and how the general factor 'family tied preferences regarding family care' affects all other variables.

\subsection{1. (Lack of) understanding of illness and cause of death}

Several Turkish and Moroccan respondents said that their terminally ill family member had not understood the diagnosis and prognosis of their disease, while they themselves did not understand it either. The diagnosis was often given by the GP just before death, so they were not prepared to organize home care. Some blamed the general practitioner for not acknowledging the seriousness of their patient's illness.

In acute situations, the patient was often brought to the hospital, where seven out of 19 died. Half of them were not aware that terminal home care might have been provided in order to let them die at home. The other half had been informed, and two patients had left the Netherlands because they preferred to die in their home country whilst another died in Turkey on his last holiday there.

It appeared that the factor 'cause of death' is also relevant to the use of home care, because some types of illness are more identifiable than others. When it was clear that the illness had progressed and the patient required the use of technical aids and nursing care, general practitioners or medical specialists made more referrals to home care and, if necessary, assisted the Turkish and Moroccan families in their request for these facilities. But when the cause of the illness was less clear, or the patient's health deteriorated rapidly, doctors and family members had often not discussed what could be done best and by whom.

In those uncertain circumstances one of the special wishes of Turkish and Moroccan patients to die in their home country(which is their cultural background), could not be considered effectively.

But when the doctor mentioned she was actually dying, he immediately added that she could not be transported anymore, as a trip reduces a patients' life with 20 days — she wouldn't even make it to the hospital in Turkey. (Turkish woman, having taken care of two mothersin-law until their death)

The fulfilling of such a wish was dependent on other factors, for example, the ties that the patient still had in his home country, and the health care facilities in that region. Some patients were welcomed by their family in Turkey or Morocco. Other patients, however, realized that the family care situation in their home country was not reliable enough. This latter group was more likely to use home care.

We then had a talk with our GP and my father-in-law, and he immediately organized a ticket, right there within $5 \mathrm{~min}$, in order to take her back to Turkey. That's where she died three weeks later. (Turkish woman, having taken care of two mothers in-law until their death)

\subsubsection{Family structure}

One might expect that in large extended families there would be enough family members to share the responsibility of care. The interviews revealed, however, that this is not a true assumption. There was limited support of family members in Morocco or Turkey and of members of the community living in the Netherlands. In some cases many relatives visited the terminally ill patient, bringing and sharing food and social talk. However, the daily physical caring was almost always carried out by one female family member.

Whenever something had to be done, it always came down to me. "Just you come to the hospital'. It's true I've always been helpful. A tradition has been built up, for me doing this now. I feel like a social worker and a little nurse at the same time. (Young mother, taking care of her Moroccan mother-in-law, besides having her own 6 children) 
Graaff, F.M. de, Francke, A.L.

Home care for terminally ill Turks and Moroccans and their families in the Netherlands:

carers' experiences and factors influencing ease of access and use of services.

International Journal of Nursing Studies: 40, 2003, nr. 8, p. 797-805

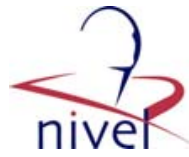

The respondents said that seeing a naked body is considered a shame in their culture and therefore is often reserved for one intimate person. In most families the physical care was a women's job. Men could provide support by shopping, organizing and transporting, but they seldom assisted the patient with activities of daily living. The principal family care giver was sometimes the patient's wife, but usually his or her daughter, or daughter-in-law.

The factor 'family structure' appeared to be quite relevant for the access to and the use of home care. The structure of Turkish and Moroccan families is different from the average Dutch family: Turks and Moroccans often have stronger ties to family members in the extended family than Dutch people. Younger members feel obliged to obey the older family members and to care for them in time of need (Van den Brink, 2000; Yerden, 2000). If necessary the daughter, or daughter in- law, who is responsible for the personal care of the terminally ill family members will move into the home of the patient, or the patient will stay in the home of his/her children. One Moroccan respondent told us that her terminally ill mother-in-law left the hospital to be cared for in her daughter-in-law's house. She did not return to her own house, because her husband was not able to care for her. The interviews confirmed the impressions that the Moroccan families are still more self-reliant while the need to use professional home care is already more prominent in Turkish families, which maybe because more Turkish women have jobs outside their home.

My four sisters work, I work part-time, I must therefore look after my parents. It was really difficult, as I also had a job. I stopped work after four months. My health worsened and I have neglected my children (Turkish woman, having taken care of her very ill mother for years).

\subsubsection{Decision making in the family}

According to the respondents their choice to use or not to use home care was strongly related to the capacity of the extended family to supply informal care. The question whether to use home care or not was often not taken by the patient, but by the (male) head of the family or the principal (female) care provider.

When the decision to use home care was delegated to the men in the family, they often argued that their family did not need any help from outside. When women were active in the decision making process, they were far more willing to ask for professional support. The illness and caring needs of the terminally ill patient sometimes evoked internal family problems. For example, when the head of the family did not want to use professional home care because this would be inviting a 'stranger' into the family home, while the principal family care giver wanted help with the daily caring activities. Some respondents regarded this tension as a cultural conflict: Turkish and Moroccan elderly will not adopt 'Dutch' mores.

My father's brother wanted to decide, as he felt he was the closest family member. I said, "No, first comes my mother and then the children, you don't have anything to do with this."' I was maybe thinking in Dutch and he in Turkish (Turkish woman taking care for her terminally ill father).

\subsubsection{Pressure from the community}

Decision making in many Turkish and Moroccan families in the Netherlands is not a matter of personal responsibility, but a family affair. As the family is part of a local and ethnic community, this social environment influences the choices made about the (home) care of terminally ill family members. Many Turkish respondents suggested that they took in sick relatives for fear of social pressure.

Ties between us are very strong. Too strong. That's why I say we sometimes need to turn ourselves into hypocrites, because many children have their in-laws come and live with them and have them cared for- not because they want it, but because of our values and traditions. Social pressure from amongst Turkish people also plays a role. (Turkish man whose wife took care of his mother until her death) 
Graaff, F.M. de, Francke, A.L.

Home care for terminally ill Turks and Moroccans and their families in the Netherlands:

carers' experiences and factors influencing ease of access and use of services.

International Journal of Nursing Studies: 40, 2003, nr. 8, p. 797-805

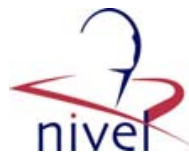

The social control of the Turkish and Moroccan community is probably stronger in the areas where a lot of Turkish and Moroccan families live. Those respondents who lived in mainly 'white' areas seem to be more open to using Dutch facilities such as home care, while respondents living in immigrant areas had to take their neighbours' opinions into account more.

\subsubsection{Information and support from informal and professional health workers}

The choice of whether or not to use home care was also influenced by the information that the Turkish and Moroccan families received about home care and other alternatives. Some of the respondents were fully informed by their general practitioner or by Turkish and Moroccan health educators. But for many respondents the most important source of information was provided by informal 'intermediaries': family members, colleagues or close friends working in the health care sector. The intermediaries not only kept these families informed, but often assisted in the process of channelling the families through the labyrinth of the Dutch health care system. This support was especially needed if the patient and his principal family care giver did not speak Dutch. The intermediaries' strength appeared to be their confidential relationship with the family, their weakness was that they were not able to inform the families about all Dutch care facilities in detail. The factor '(lack of) information' will have greater influence on the access to and use of home care if the Turkish or Moroccan family members are not able to read or understand the Dutch language.

\subsubsection{Formal referrals}

The introduction to Dutch home care is often given by the general practitioner. Patients, who had first been in hospital, were sometimes referred to home care by their medical specialist. The respondents assumed that doctors who could refer them to home care, sometimes did not do so because they had the impression that these Turkish and Moroccan patients could be cared for sufficiently by their family. Perhaps they did not realize that although a lot of family members were gathered when they visited the family, each family member had his own reason to be present. For example, to represent the family officially, or to interpret the discussions or to drive other family members to this meeting. Doctors, however, often did not meet the female family member who was responsible for providing physical care giving, so they were unable to measure the home care burden on the principal care giver. The female respondents in this research felt that general practitioners and other assessment consultants should take their needs into account.

In the experience of some respondents their general practitioner was committed to informing the family and to organizing tailor made home care. One very dedicated general practitioner made it possible for her heart and lung patient on holiday in Morocco, to get extra bottles of oxygen, via the Social Health Insurance Office in Rabat, up to the airport at Oujda near the border of Algeria, so that he could die in his village near Oujda, united with all his children some of whom lived in the Netherlands, some in Morocco. This general practitioner not only informed her patient very well, she also obtained all the necessary information for herself in order to treat the patient optimally. Her dedication to this patient and her advice to use home care to ease the family situation in the terminal phase is well known in the Moroccan community in this town.

\subsubsection{Conclusions and discussion}

Our study indicates that those Turkish and Moroccan terminal patients and their relatives who do use Dutch professional home care are often satisfied with the care received. In particular, they appreciate the loan of equipment and the practical support of the home care personnel. Although some Turkish and Moroccan respondents observed friendly and less friendly professionals, in general they were positive about the nurses delivering home care. In fact, the Moroccan and Turkish respondents were often more satisfied with the communication of the nurses of the home care organization, than with general practitioners. Within the Turkish and Moroccan families unwritten rules tell everybody when to speak and to whom (for example, when speaking about imminent death). General practitioners were often not aware of these culturally defined patterns of behaviour, nor of their giving offence to the patients and their families. Nurses had more understanding of these unwritten codes. Perhaps nurses prevent communication problems by taking more time to share the family sorrows, taking part in daily life and to comfort the relatives and patient. In this process the non-verbal physical contact with the 
Graaff, F.M. de, Francke, A.L.

Home care for terminally ill Turks and Moroccans and their families in the Netherlands:

carers' experiences and factors influencing ease of access and use of services.

International Journal of Nursing Studies: 40, 2003, nr. 8, p. 797-805

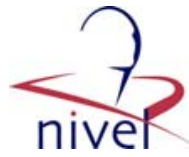

patient may have played an important role. More contact over a longer period may have resulted in the positive opinion of the respondents about the nurses compared to their critical judgement of some general practitioners.

The data also revealed that terminally ill Turks and Moroccans and their relatives are often restrained about using professional home care. This is caused by several factors. An important factor which inhibits their access to and use of Dutch home care is the fact that the patients and relatives are often not aware that the patient will die soon. They are unaware that the symptoms and problems in the terminal phase will probably worsen, which will make professional home care necessary. Whether this is specific for Turkish and Moroccan immigrants is, however, questionable. In the study of Francke and Willems (2000) among Dutch terminally ill patients it was found that many patients and their relatives were not aware of the fact that the patient would soon die, which sometimes also resulted in crisis situations in which no home care was organized.

Another main factor which inhibits Turks and Moroccans from using Dutch home care is the wish of the terminally ill patient to die in their home country. Although many patients are unable to fulfil this wish, this can be a reason for the fact that patients and relatives do not consider the possibilities of Dutch (home) care facilities.

In addition, the belief in Turkish and Moroccan communities that (female) family members are obliged to care for terminally ill relative seems to be related to a limited use of professional home care, men in particular often arguing that their family does not need any outside help. Women however are more open to receive support from external professionals, as they often carry the heaviest responsibility for physical care.

The social environment also strongly influences the use or non-use of professional help. This study and the studies performed by Van Toorn (1994) and Yerden (2000) suggest that feelings of honour and shame may inhibit the use of professional home care. The study also reveals that social control seems to be weaker in "white" areas, where Turkish and Moroccan families maybe more willing to accept professional home care than their brethren in areas with a larger Turkish and Moroccan population.

This study, and the studies of Beljaarts (1997) and Yerden (2000) show that Turkish and Moroccan patients and relatives are not well acquainted with the Dutch (home) care system, and that where they had received information about home care, it was often delivered by informal intermediaries.

General practitioners often do not refer Turkish and Moroccan families to home care, even when the burden of care is too heavy for the family caregivers, possibly because they think that close family ties ensure that there are enough family members to care for the terminal patient. This study indicates, however, that despite the often-large families and the close ties within the family, the direct care is often provided by one female family member for whom this experience is a hard and stressful duty. General practitioners should arguably inform terminal Turkish and Moroccan patients and their relatives about the possibilities of professional home care, which may help prevent Turkish and Moroccan patients being admitted to hospital to die, when home care is not organized in time.

An important question is whether these findings are specific to the situation of Turkish and Moroccan terminally ill patients and their relatives in the Netherlands? Are there similarities to (a) terminally ill Turkish and Moroccan patients and their relatives living in their home country or in other countries, and (b) other immigrant groups living in the Netherlands or in other European countries? Despite an intensive literature search the author found no studies which addressed the former, whilst there were a few relevant studies in relation to the latter (Gaffin et al., 1996; Spruyt, 1999). Stevens et al. (1994) describe the willingness and expectations for giving family care in Morroccan and Dutch families. They concluded that in general the Morroccan were more willing to care for their elderly (including terminally ill) family members than Dutch people, but many potential family carers expected problems in combining family life, a job and the care of their parents. This seems in line with the results of this study which shows that female family carers were very willing to take care of their terminally ill relative, but experienced this as a very heavy task which was often difficult to combine with the care of their own children or household.

Another relevant study is the one performed by Gaffin et al. (1996). These researchers described the results of a campaign of the National Council for Hospice and Specialist Palliative Care Services in London, to provide specialist palliative care by a network of home care, day care and hospital care in 
Graaff, F.M. de, Francke, A.L.

Home care for terminally ill Turks and Moroccans and their families in the Netherlands: carers' experiences and factors influencing ease of access and use of services.

International Journal of Nursing Studies: 40, 2003, nr. 8, p. 797-805

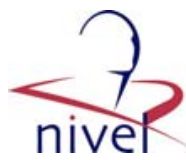

three areas with high ethnic populations. The study also concluded that a more culturally sensitive service provision is recommended.

Finally, in a study of Spruyt (1999) into the palliative care experiences of 18 Bangladeshi patients and family carers in London were described. As in this study, Spruyt found that family carers sometimes do not agree with the disclosure of the diagnosis to the patient. Nearly all patients mentioned communication problems with professional staff, because they did not understand the English language and had to rely on family members for translation. Spruyt concluded that many patients suffered from poorly controlled symptoms and pain.

It is remarkable that all studies mentioned indicate that terminally ill patients of ethnic minorities face serious care problems, which often cannot be fully dealt with by their relatives. As a result of these findings, it is recommended that home care organizations and referrers (e.g. general practitioners) provide more information about the available home care to terminally ill patients and their relatives with a Turkish, Moroccan or other immigrant background.

\section{ACKNOWLEDGEMENTS}

This study was supported by a Grant of The Netherlands Organization for Health Research and Development (ZonMw), within the Program of Palliative Care.

\section{REFERENCES}

Adam, S.G.M., Hutten, J.B.F., 2001. The Netherlands, In: Philp, I. (Eds.), Family Care of Older People in Europe. IOS Press, Amsterdam.

Beljaarts, M.A.M.M., 1997. Zorg voor allochtone ouderen. Instituut voor Sociaal Economisch Onderzoek, Rotterdam.

van den Brink, Y., 2000. Transculturele Familiezorg Thuis, Zorgpraktijken en—opvattingen van Turkse mantelzorgers in Rotterdam. KCW Rotterdam, Rotterdam.

CBS, Central Bureau of Statistics in the Netherlands, Statline, consulted on internet on 9-4-2002.

Francke, A.L., Willems, D.J., 2000. Palliatieve zorg vandaag en morgen, feiten, opvattingen en scenario's. Elsevier, Maarssen.

Gaffin, J., Hill, D., Penso, D., 1996. Opening doors: improving access to hospice and specialist palliative services by members of the black and minority ethnic communities. Commentary on palliative care. British Journal of Cancer Supply29, 51-53.

Glaser, B.A., Strauss, A.L., 1967. The Discovery of Grounded Theory: Strategies for Qualitative Research. Aldine Publishing Company, Chicago, IL.

Lincoln, Y.S., Guba, E.G., 1985. Naturalistic Inquiry. Sage, BerverlyHills.

Maravelias, S., 2000. Allochtoon personeel en allochtone cliënten bij algemene ouderenvoorzieningen in de stad Utrecht, Utrecht.

Spruyt, O., 1999. Community-based palliative care for Bangladeshi patients in east London. Accounts for bereaved carers, Palliative-Medicine, Edward Arnold Ltd., England, pp. 119-129.

Strauss, A.L., Corbin, J., 1990. Basics of Qualitative Research, Grounded Theory Procedures and Techniques. Newbury Park, Sage Publications, London.

Stevens, F.C., ten Have, M.L., Philipsen, H., Serpenti, L., Elmas, T., 1994. Familiezorg voor Molukse en Nederlandse ouderen: een vergelijkend onderzoek naar bereidheid en verwachtingen, Tijdschrift Sociale geriatrie, The Netherlands, pp. 184-191.

van Toorn, M., 1994. Allochtone ouderen: een zorg(e)loze toekomst? Onderzoek naar de ervaringen in Rotterdamse zorg-,hulp en dienstverlenende instellingen, Rotterdam.

Yerden, I., 2000. Zorgen over zorg. Traditie, verwantschapsrelaties, migratie en verzorging van Turkse ouderen in Nederland, Amsterdam. 
Graaff, F.M. de, Francke, A.L.

Home care for terminally ill Turks and Moroccans and their families in the Netherlands:

carers' experiences and factors influencing ease of access and use of services.

International Journal of Nursing Studies: 40, 2003, nr. 8, p. 797-805

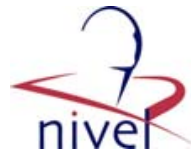

\section{TABLE AND FIGURE}

Table 1

Characteristics of the relatives and their terminally ill patients

\begin{tabular}{|c|c|c|c|c|c|c|c|c|}
\hline No. & $\begin{array}{l}\text { Nationality } \\
\text { patient }\end{array}$ & Sex & $\begin{array}{l}\text { Relation of } \\
\text { respondent to } \\
\text { patient }\end{array}$ & $\begin{array}{l}\text { Use of } \\
\text { interpreter }\end{array}$ & $\begin{array}{l}\text { Illness and } \\
\text { cause of death }\end{array}$ & $\begin{array}{l}\text { Patient living } \\
\text { with respondent }\end{array}$ & $\begin{array}{l}\text { Place of death } \\
\text { care }\end{array}$ & $\begin{array}{l}\text { Use of } \\
\text { home }\end{array}$ \\
\hline 1 & $\mathrm{~T}$ & w & D. in law & - & Liver sickness & + & Turkey & - \\
\hline 2 & $\mathrm{~T}$ & w & D. in law & - & Kidney sickness & + & Hospital & - \\
\hline 3 & $\mathrm{~T}$ & w & Son & - & Stroke & - & Still alive & + \\
\hline 4 & $\mathrm{~T}$ & $\mathrm{~m}$ & Daughter & - & $\begin{array}{l}\text { Cerebral } \\
\text { haemorrhage }\end{array}$ & - & Still alive & + \\
\hline 5 & M & $\mathrm{m}$ & Daughter & + & Heart failure & + & Hospital & - \\
\hline 6 & M & $\mathrm{m}$ & Wife & + & Liver cancer & + & Hospital & - \\
\hline 7 & M & $\mathrm{m}$ & Wife & + & Liver sickness & + & Hospital & - \\
\hline 8 & M & $\mathrm{m}$ & Wife & - & Heart disease & + & Morocco & + \\
\hline 9 & M & w & Daughter & + & Cervical cancer & + & At home & + \\
\hline 10 & M & w & Son & + & $\begin{array}{l}\text { Infirmities of } \\
\text { old age }\end{array}$ & + & At home & + \\
\hline 11 & $\mathrm{~T}$ & $\mathrm{~m}$ & Daughter & + & Lung cancer & Partly & Turkey & + \\
\hline 12 & $\mathrm{~T}$ & $\mathrm{w}$ & Daughter & - & Brain tumour & - & Nursing home & - \\
\hline 13 & $\mathrm{~T}$ & $\mathrm{w}$ & Daughter & - & Heart failure & Partly & Nursing home & - \\
\hline 14 & $\mathrm{~T}$ & w & $\begin{array}{l}\text { Son and D. in } \\
\text { law }\end{array}$ & - & $\begin{array}{l}\text { Sickness of } \\
\text { kidney, lung } \\
\text { and heart }\end{array}$ & + & At home & + \\
\hline 15 & M & $\mathrm{m}$ & Wife & - & Lung cancer & + & At home & + \\
\hline 16 & $\mathrm{~T}$ & $\mathrm{~m}$ & $\begin{array}{l}\text { Parents and } \\
\text { sister }\end{array}$ & - & Brain disease & - & Hospital & - \\
\hline 17 & M & w & D. in law & - & $\begin{array}{l}\text { Intestinal } \\
\text { cancer }\end{array}$ & Partly & At home & + \\
\hline 18 & M & $\mathrm{m}$ & Children & - & Liver cancer & + & Hospital & - \\
\hline 19 & M & $\mathrm{m}$ & Wife & + & Liver sickness & + & At home & - \\
\hline
\end{tabular}

$\mathrm{T}=$ Turkish, $\mathrm{M}=$ Moroccan, $\mathrm{m}=$ man, $\mathrm{w}=$ woman, $\mathrm{D}$. in law $=$ daughter in law.

+ , positive in this characteristic; - , negative in this characteristic.

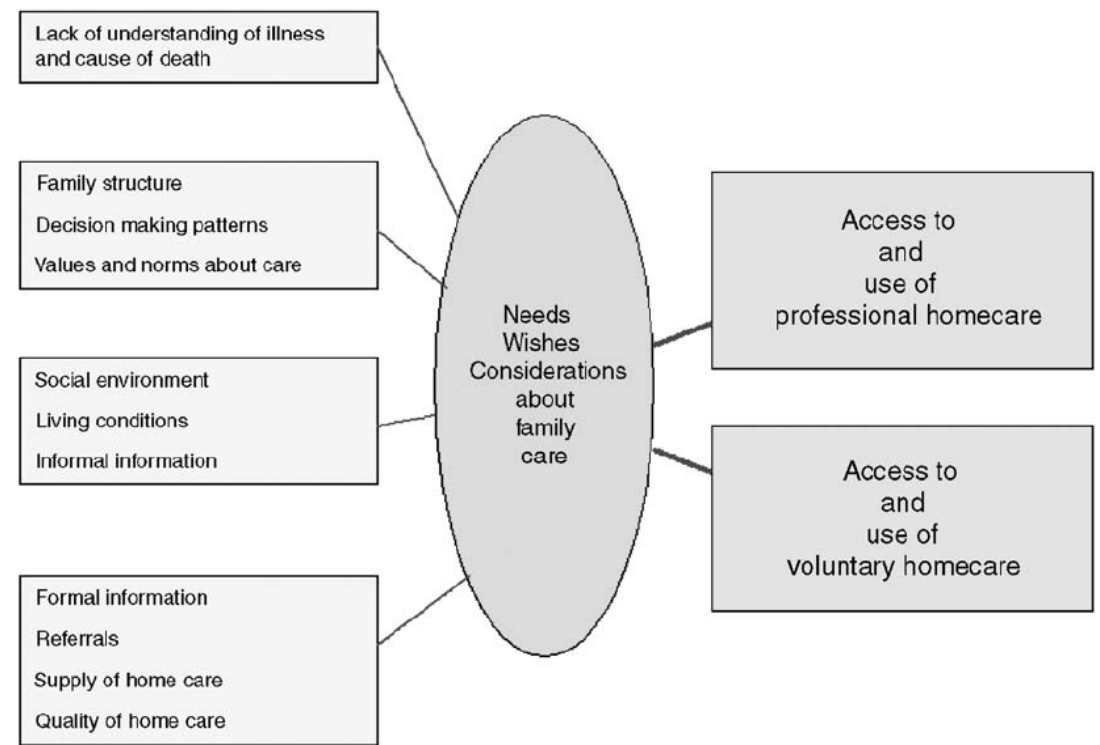

Fig. 1. Variables affecting access to and use of home-care. 